\title{
A HISTÓRIA DOS CRISTÃOS-NOVOS NO BRASIL COLONIAL: ESCRITA E REPRESENTAÇÕES NOS LIVROS DIDÁTICOS NOS ÚLTIMOS VINTE ANOS
}

\author{
THE HISTORY OF THE NEW-CHRISTIANS IN THE COLONIAL BRAZIL: \\ WRITING AND REPRESENTATION IN THE TEXTBOOKS (1980 - 2007)
}

Helena Ragusa ${ }^{1}$

\begin{abstract}
RESUMO: Neste trabalho, propõe-se realizar uma reflexão das representações encontradas em alguns livros didáticos do ensino fundamental e médio no que se refere ao estudo do período colonial, em especial, os cristãos-novos entendendo-os como sujeitos históricos atuantes na formação da sociedade brasileira. O objetivo é refletir sobre a escrita que vem sendo produzida em torno desses personagens nos últimos 20 anos, de forma a observar as diferenças e semelhanças entre as obras escolhidas, e em que medida esses saberes estão dialogando com a nossa historiografia. Os cristãos-novos, que em tais livros são apresentados de forma não problematizada, simplista e naturalizada, foram responsáveis não só por grande parte do desenvolvimento econômico ocorrido logo nos primeiros anos, como também pelas heranças deixadas na sociedade e que até hoje se fazem presentes.
\end{abstract}

Palavras-chave: História e Ensino. Livros Didáticos. Escrita. Representações.

\begin{abstract}
This work studies the reflection of these representations found in some textbooks adopted for the medium and high school system. These representations refer to the study of the colonial period, most particularly to the New-Christians, bearing in mind that these historical characters lived and acted within the Brazilian society. The main purpose of this work is the reflection upon the writing that has been done about these characters during the last 20 years. This will allow us to observe the differences and similarities among the chosen works and up to a point, how this knowledge is related to our historiography. The New-Christians - that in the textbooks are not presented in-depth, but rather in a superficial way - were responsible not only for a great portion of the economic development occurred in the early times, but also for the contribution given to the society which is still part of our present.
\end{abstract}

Keywords: History and Teaching. Textbooks. Writing. Representation.

\footnotetext{
${ }^{1}$ Mestranda em História Social pela Universidade Estadual de Londrina.
} 
Este estudo constitui-se em parte de uma pesquisa em andamento que tem como material de análise a questão da representação dos cristãosnovos na escrita produzida pelos livros didáticos. Uma das finalidades é trabalhar com a ideia de que tais personagens tiveram uma intensa participação no processo de formação da sociedade brasileira, e, durante todo o período colonial. Também proporcionar outro olhar para os conteúdos apresentados nesses materiais em relação aos cristãos-novos e ao papel que exerceram aqui.

Refletindo acerca das problematizações que envolvem o estudo desse tipo de ensino, depreende-se que os avanços no sentido de uma aproximação mais consistente entre saber acadêmico e o saber escolar é demasiado tímido. Fanaia (2008, p.13- 22), buscando um diálogo entre História, saber acadêmico e saber escolar, entende a formação universitária e ensino fundamental e médio como duas faces de uma mesma moeda, porém paradoxalmente postos em dois mundos que são próximos ao mesmo tempo que distantes.

Ainda que as abordagens feitas pelos livros didáticos pareçam corresponder às novas tendências historiográficas, a distância é visível. A presença dos cristãos-novos no Brasil Quinhentista, por exemplo, embora bastante conhecida e estudada pela nossa historiografia, no que se refere à literatura didática, é pouco explorada levando-nos então a alguns questionamentos em relação à forma como a História do Brasil, mais especificamente, da formação da sociedade brasileira vem sendo apresentada. A impressão que se tem a respeito do livro didático é que a construção de identidades hegemônicas não foram superadas:

A crítica fundamental e que tem sido repetida inúmeras vezes por historiadores, especialmente os que se dedicam ao ensino, é a de que a História do Brasil tem sido ensinada visando construir um passado único e homogêneo, sem atentar para os diferentes setores sociais e étnicos que compõe a sociedade brasileira (BITTENCOURT, 2003, p. 198).

O fato é que os cristãos-novos ou descendentes dos mesmos quando aportaram em solo brasileiro, vieram muitos deles, com a missão de 
participar do projeto colonizador português ocupando até mesmo, cargos de confiança a mando do rei.

Assumindo o livro didático enquanto documento, ao realizar uma leitura crítica, o historiador deverá inquirir o que os textos revelam sobre o fato a ser estudado ou investigado, lembrando que: "Restabelecer as tênues vozes de indivíduos perdidos entre fragmentos de documentação permite reconhecer a diversidade humana dentro da História; conferir dignidade ao relato miúdo, e até ouvir de outra forma vozes consagradas de grandes personagens" (BELLOTTI, 2005, p. 15).

É certo que a prática historiográfica alterou-se de forma significativa nas últimas décadas do século XX, surgindo então novos objetos, sujeitos, problemas e abordagens, além de uma verdadeira renovação no que se refere aos temas que até então eram ausentes na História, como por exemplo, o estudo das mentalidades, da criança, do medo, das tradições, questões essas que modificaram o lugar da história, isto é, deixou de pertencer ao grupo das disciplinas dominantes. O objetivo passou a ser identificar como em diferentes espaços e tempos uma determinada realidade social é pensada e construída agregando o trabalho do historiador a outros saberes, como a sociologia, a antropologia e a literatura, calcando a história em novos princípios de legitimidade, além daqueles que Ihe são inerentes.

Percebida a inserção do cristão-novo em algumas obras didáticas da década de 1980 e aquelas mais contemporâneas, verificamos um esforço dessa aproximação entre a historiografia e o conhecimento histórico escolar. Porém, o que nos preocupa é a forma como esse saber, no caso, da presença cristã-nova no Brasil foi e vem sendo apropriada, e, em que contexto está sendo representado.

Para tanto, selecionamos alguns dos livros aprovados pela comissão composta pelo Fundo Nacional de Desenvolvimento da Educação (FNDE) do governo federal, destacando, no caso das coleções atuais, aqueles que tiveram uma maior circulação e que também, nortearam minha prática em sala de aula, enquanto professora tanto do ensino Fundamental, quanto do Ensino Médio. Assim, pautamos nossa pesquisa por meio desses critérios ao 
definirmos nossa fonte a ser pesquisada e nela investigarmos o lugar do cristão-novo na História do Brasil, mais especificamente, ao início dela.

Correspondendo ao primeiro recorte de tempo - 1980 - focaremos nossa análise nas obras de Raymundo Campos História do Brasil e Francisco de Assis Silva e Pedro Ivo de Assis Bastos História do Brasil: Colônia, Império e República, ambos voltados para o $2^{\circ}$ ano do Ensino Médio.

Já no que tange ao contexto contemporâneo, selecionamos três obras, sendo duas delas parte de uma coleção, a primeira delas, História em projetos Velhos mundos e mundos novos: encontros e desencontros do século XV ao XVIII, das autoras Conceição Oliveira, Carla Miucci e Andrea Paula, conteúdo programático voltado para a $6^{a}$ série que corresponde atualmente ao 70 ano do Ensino Fundamental ${ }^{2}$, e, voltada para o Ensino Médio, sobre a autoria de Antônio Pedro e Lizânias de Souza Lima, História da Civilização Ocidental, ambas buscando pautar-se na abordagem de uma História Integrada. Também, direcionado o Ensino Médio, o livro de Roberto Catelli Junior, História: texto e contexto, sobre a perspectiva de uma História temática.

Ressaltamos que os livros aqui em questão foram editados pelas principais editoras de livros didáticos da década de 1980, da mesma forma que com aqueles que correspondem aos dias atuais: Moderna, Atual, Ática, Scipione, e FTD.

No que diz à literatura didática utilizada pela comunidade judaica, focaremos nossa análise a um estudo de caso, ou seja, a uma obra específica da década de 1970, de Renato Mezan, Caminhos do povo judeu, destinado ao Ensino Médio, mais especificamente ao 30 ano, buscando compreender como se constrói a escrita da historia em torno dos neocristãos quando esses estavam aqui no período colonial.

Sobre a utilização do livro didático de História do Paraná, nossa pesquisa se deu em torno do chamado Livro Público do professor, dentro de uma proposta bastante inovadora, destinado a princípio, apenas para as três últimas séries do ensino médio.

\footnotetext{
${ }^{2}$ Como colocado no verso da obra, "História em projetos foi a única coleção de História que recebeu conceito ótimo em todos os critérios de avaliação PNLD/2008".
} 
Num primeiro momento, buscamos o entendimento de Abud, sobre a forma em que são construídas as narrativas didáticas, ou seja, de maneira simples e compreensível, haja vista o público ao qual se destina, no caso, a clientela escolar (ABUD, 1986: 81). No entanto, a autora chama a atenção para os cuidados que se deve ter durante esse processo, evitando o aparecimento de distorções ou exclusões.

Em nossa análise foi possível identificar, como veremos mais adiante, que mesmo havendo evidências documentais sobre a participação dos cristãos-novos na formação da sociedade colonial, tais livros, não trazem em sua escrita uma preocupação em dimensionar, aprofundar ou descrever sobre a atuação e os diferentes papéis assumidos por esses personagens na colônia luso - portuguesa.

Num primeiro momento, buscamos o entendimento de Kátia Abud (1986, p.81) sobre a forma em que são construídas as narrativas didáticas, ou seja, de forma simples e compreensível, haja vista o público ao qual se destina, no caso, a clientela escolar. No entanto, a autora chama a atenção para os cuidados que se deve ter durante esse processo, evitando o aparecimento de distorções ou exclusões.

Em nossa análise foi possível identificar - como veremos mais adiante - que mesmo havendo evidências documentais sobre a participação dos cristãos-novos na formação da sociedade colonial, além das exclusões, existem distorções daquilo que eles realmente representavam fosse no aspecto político, econômico, cultural ou religioso.

Oliveira (2007, p. 68), define a escrita como um artefato que pode problematizar as memórias elaboradas historicamente e lançar questionamentos sobre aquilo que se convencionou chamar de memória cristalizada; como uma prática que institui rostos. Por se tratar de um artefato bastante utilizado no processo de ensino e aprendizagem, o conhecimento produzido pelo livro didático acaba, muitas vezes não sendo questionado, como se as realidades que se apresentam nos textos fossem mudas e não pertencessem a lugar ou tempo algum.

Objetivou-se dimensionar a relevância dispensada ao tema da participação dos cristãos-novos na formação de nossa sociedade, pois como 
já apontado não se trata de uma "presença esvaziada"13, mas ao contrário, bastante atuante.

Refletindo acerca da forma como os cristãos novos estão inseridos nos textos propostos, não foi possível verificar uma preocupação dos autores em investigar, ampliar ou discutir o papel desses sujeitos na História da formação do Brasil:

No princípio da colonização, quando tudo era insipiente e difícil, os elementos mais esclarecidos tinham que ser aproveitados, pois do contrário nem se estabeleceria o municipalismo, conforme preceituara o regime das donatárias. Afora a nação hebréia, raras as pessoas sabiam redigir uma carta, pelo menos. As próprias autoridades sentiam-se na necessidade de recorrer a tal gente, sem levar em conta etnia, ou a condição de exilado ou se exercia atividade mecânica. (SALVADOR, 1978, p. 127)

Este é apenas um dos exemplos que demonstra a importância, que os cristãos-novos representavam para a metrópole portuguesa. Não só a serviço da Coroa, mas também, envolvidos em diversas funções, os neocristãos foram se estabelecendo, passando a fazer parte do cotidiano da população a qual estavam inseridos, conforme mostram os estudos.

\section{A Trajetória Historiográfica em Torno Do Cristão-Novo na Colônia Brasileira.}

A partir da segunda metade do século XVI, um grande fluxo de judeus neoconversos oriundos da Espanha e de Portugal, chegava ao Brasil fugido de perseguições ibéricas. O ano de 1390 teria sido a década-chave para se compreender o surgimento do fenômeno dos conversos que atravessaria $\mathrm{o}$ país no século $\mathrm{XV}$, irradiando-se posteriormente para Portugal. Nessa época, uma onda massiva de conversões ao catolicismo fez surgir à comunidade marrana ou conversa de Espanha, até que no ano de

\footnotetext{
${ }^{3}$ A expressão foi utilizada por Luis Felipe Miguel no artigo, Retrato de uma ausência: a mídia nos relatos da história política do Brasil. In: Artigo. Revista Brasileira de História. São Paulo, v. 20, n 39, p.190-199. 2000.
} 
1492, foi decretada a expulsão geral. Apesar das controvérsias historiográficas sobre as causas da proibição do judaísmo em Portugal, o fato é que a comunidade de cristãos-novos em Portugal formou-se no ano de 1496, quando sobre as ordens do rei D. Manuel, os portugueses assistiram à conversão forçada de milhares de judeus batizados em pé. (VAINFAS; HERMANN, 2005, p. 35).

O objetivo era se livrar do estigma de cristãos-novos sem que fosse preciso se adaptar a uma realidade muito diferente daquela que já estavam habituados, mantendo a língua e a organização social, como foi o caso do Brasil que possuía tais características:

\begin{abstract}
Aqui, eles trabalharam, enriqueceram ou empobreceram, como outros migrantes Vigiados por um tribunal católico, mais de um milhar foi processado por costumes familiares, que então eram considerados crimes sob o nome de "culpas do judaísmo", presos ou desterrados para a metrópole, vinte e um deles foram assassinados legalmente e muitos outros morreram nas prisões infectadas (VALADARES, 2007, p. 24).
\end{abstract}

Desempenharam os mais diversos papéis nos diferentes setores da sociedade desde os primórdios da colonização até os dias de hoje, "com a ocupação territorial e a exploração econômica do açúcar, sobretudo no Nordeste, a importância desses personagens seria notável" (VAINFAS; ASSIS, 2005, p. 45).

Foi mais precisamente durante as décadas de cinquenta e sessenta que os estudos começaram a tratar da presença dos cristãos-novos em nosso território. A perspectiva trazida por eles era de que o Brasil seria uma excelente rota de fuga, e, os cristãos-novos seriam então, os mártires da Inquisição, entendidos como elemento não adaptado à nova realidade ibérica (SILVA, 2007, p.10).

Nessa mesma época a pesquisa histórica em torno do cristão-novo no Brasil, cresceu não só em quantidade, mas também em qualidade a partir das inúmeras contribuições dos estudos dedicados ao período colonial. Alguns trabalhos referiam-se ao Brasil como um lugar de excelentes oportunidades de enriquecimento, compreendendo que essa seria uma razão bastante forte para que os judeus batizados tivessem interesse em se 
estabelecer no país na esperança de encontrar um ambiente próspero e favorável. (SALVADOR, 1976, p.48).

Apesar de haver uma maior documentação sobre a participação dos neocristãos no nordeste açucareiro, Salvador (1978, p. 379), parte de um trabalho voltado para a economia interna das capitanias do Sul, que teriam desempenhado um papel notável no Atlântico Meridional dentro da conjuntura econômica portuguesa, concentrando seus estudos na área compreendida pelos atuais estados do Espírito Santo, São Paulo e Rio de Janeiro.

Dentre os vários trabalhos voltados para a presença do cristãosnovos no Brasil, Novinsky novamente, em outro trabalho (2001) num estudo publicado sobre os cristãos-novos na região de Minas Gerais no século XVIII, aponta para uma grande diversidade de comportamento desses agentes, além de uma rica atuação nos diversos setores que comportavam a sociedade na época, segundo ela "as atividades que passaram a exercer no país ${ }^{4}$ indicavam sua rápida inserção na sociedade, estabelecendo relações que ao longo do tempo foram se consolidando".

Com o passar do tempo, a produção historiográfica ampliou-se e cada vez mais surgiam indícios de que a participação dos cristãos-novos na história nacional havia sido bem mais complexa do que se supunha, não se limitando apenas à um determinado setor, nem tampouco à um único espaço, "a mobilidade dos cristãos-novos na colônia brasileira foi freqüente e ininterrupta" (NOVINSKY, 2001, p. 168).

Já Francisco Moreno de Carvalho, por exemplo, ao estudar a presença dos cristãos-novos no Rio de Janeiro do século XVIII, remete-se a eles como homens de negócio, diretamente ligados à atividade agrícola do açúcar enquanto senhores de engenho e donos de escravos, ao mesmo tempo, em que também atuavam em outras atividades como, médicos e advogados. De acordo com o autor, os cristãos-novos que moravam no Rio de Janeiro nessa época, viviam nas mesmas ruas ocupadas pela camada

\footnotetext{
4 Anita Novinsky, tida como pioneira no assunto, abriu novos horizontes para a pesquisa histórica acerca da questão judaica no Brasil. Grande parte de sua produção, demonstra as várias atividades exercidas pelos cristãos-novos ao longo do período colonial e além dele, como é o caso da obra em questão. Esse é o caso da obra "Cristãos-Novos na Bahia: A Inquisição", "Inquisição: prisioneiros do Brasil, séculos XVI a XIX".
} 
elitista, encontrando-se entre os mais ricos senhores da época. (CARVALHO, 2005, p. 145-146).

Ao perceber o considerável aumento no número de cristãos - novos que aportavam aqui, estudos começaram a surgir na historiografia brasileira redimensionando o lugar que estes passaram a ocupar no passado colonial, isto é, entendendo-os como agentes históricos, sujeitos de sua própria ação ${ }^{5}$. O sentido de se narrar uma história sobre tais personagens no mundo luso-brasileiro seria compreender sua atuação na sociedade e as dificuldades que enfrentaram diante das perseguições que sofreram por parte da mesma e pela Inquisição, indicando resistências em relação à cultura $^{6}$ e à religião que lhes eram impostas.

O "sincretismo religioso", característica marcante da colônia brasileira, onde toda a diversidade cultural e religiosa era vivida e, portanto, inserida no dia-a-dia das populações que aqui se encontravam, apresentava traços católicos misturados a outras formas de crença, estando entre elas, o judaísmo.

Assim, as relações cotidianas que ao longo do tempo foram se consolidando entre cristão-novos e os demais habitantes da colônia tornaram-se objeto de uma grande variedade de estudos. As manifestações culturais da religião foram transmitidas de uma geração para outra, e, embora existam aqueles que apontem para certo afastamento do judaísmo, é possível perceber que a prática da tradição judaica não foi abandonada, e aos poucos, não todos, mas alguns neoconversos trataram de inseri - lá na esfera pública à qual pertenciam. Nesse caso, seria interessante observar que cada cristão-novo criou uma individualidade própria, com características e especificidades próprias também. Muitos cristãos-novos, de fato, deixaram o judaísmo de lado, tentando aceitar o cristianismo, renegando o judaísmo, descontentes com as desconfianças de que eram vítimas por carregarem o sangue de um neocristão.

\footnotetext{
${ }^{5}$ Além dos estudos realizados pela historiadora Anita Novinsky, outros estudiosos contribuíram para a constituição de uma historiografia judaica no Brasil, como é o caso José Gonçalves Salvador (1976), Sônia Siqueira (1978), Egon e Frieda Wolff (1975), Elias Lipiner (1977), etc.

6 O conceito de cultura o qual nos referimos seria aquele defendido por Geertz (1989) a partir de Max Weber, ou seja, como uma teia de significados.
} 
A ocorrência do criptojudaísmo e sua intensidade variam no tempo, no espaço e em cada caso. Quanto mais próximos do período em que ocorreu a conversão forçada, mais possível encontrarmos cristãos-novos judaizantes. Com o tempo, muitas práticas e o conhecimento do judaísmo pelas novas gerações foram caindo no esquecimento. O que sobreviveu mesmo, mais do que o criptojudaísmo, é uma identidade marrana, um sentimento de pertença a um grupo que é vítima de preconceitos e perseguições sociais as mais diversas.

Devemos ressaltar que o estudo do neocristão no Brasil colonial não é tarefa simples, visto que sua origem está dissolvida entre os povoadores e imigrantes portugueses, confundindo-se entre eles ${ }^{7}$. Contudo, o interesse de estudiosos que buscam compreender as diversas maneiras do cristãonovo lidar com essa ascendência, suscitou pesquisas voltadas para as movimentações e adaptações decorrentes da expulsão e conversão forçada ao cristianismo, assim como os múltiplos comportamentos possíveis, enquanto mantenedores ou não da cultura judaica.

Nesse sentido, foi se abrindo e abre-se ainda cada vez mais, um universo de possibilidades, haja vista, as inúmeras fontes existentes que tornam possível identificar e desvendar os papéis desenvolvidos por tais personagens em nosso território, relacionados aos costumes, ao comportamento e às tradições que eles traziam.

A começar pela conversão forçada a qual os cristãos-novos foram submetidos, leituras recentes apontam para o fato de que esse processo não foi determinante para que os judeus abandonassem seus hábitos $e$ costumes. Havia sim aqueles que membros de uma mesma família seguiram caminhos diferentes, isto é, alguns optando por permanecerem dentro do cristianismo, professando-o com convicção, mas eram muitos aqueles que ignorando o batismo forçado decidiram pela volta às raízes judaicas, ou retornavam a elas na primeira oportunidade. (PERNIDJI, 2005, p. 63 ).

\footnotetext{
7 Valadares num estudo sobre a genealogia dos cristãos-novos no Brasil nos possibilita ter uma boa dimensão de como se deu a sucessão genealógica dos judeus convertidos em 1497 e os descendentes cristãos-novos no Brasil, ocultados pelos mecanismos de assimilação criados pelo Estado. (VALADARES, 2007)
} 
Ainda que estivessem frente a duas realidades incompatíveis, uma cristã e a outra judaica grande parte dos cristãos-novos vivenciavam o judaísmo secretamente, ou em alguns casos, no sentido de sobrevivência, acabaram transformando suas tradições religiosas.

Os documentos derivados dos procedimentos inquisitoriais contra a prática do judaísmo, dentre eles as listas provenientes dos autos-da-fé, constituem um rico material, na medida em que carregam não só elementos ligados à religiosidade dos neocristãos, mas também relacionados à sua vida cotidiana em seus mais corriqueiros aspectos, fornecendo ao pesquisador um vasto campo a ser investigado. Talvez, a fragilidade da estrutura eclesiástica na América Portuguesa e a distância da vigilância e do risco de punição inquisitorial favoreceram a continuidade da religião proibida (HERMANN, 2005, p.90). Em contrapartida, há aqueles que consideram a ligação com a fé judaica razão suficiente para que a tradição não fosse esquecida, levando para as prisões portuguesas centenas de cristãos-novos acusados de criptojudaísmo ${ }^{8}$.

Mas, o fato, porém, é que esses documentos, essas fontes, propiciaram e propiciam ao historiador desvendar outras faces do neoconverso e de sua atuação no Brasil Português, de maneira que sua presença não seja entendida apenas dentro de uma perspectiva. Por de trás das atividades exercidas pelos cristãos-novos no Brasil enquanto colônia, muitos elementos culturais e religiosos - se codificados - podem revelar a existência de uma memória histórica que legitima a importância de se estudar a presença desses personagens na construção do Brasil.

\section{O Lugar dos Cristãos-Novos na Escrita do Livro Didático}

\footnotetext{
8 É sabido que a abordagem do Santo Ofício sobre os cristãos-novos na Europa foi muito mais violenta gerando um grande número de mortes. Contudo, é fato que as perseguições sofridas pelos que aqui se encontravam levou a uma perda significativa da cultura judaica.
} 
Ao contrário do que pode nos oferecer as diferentes pesquisas realizadas a respeito da história do cristão-novo no Brasil colonial, a escrita produzida nos livros didáticos acerca desses agentes acabam limitando e restringindo a importância de sua atuação no território.

Quando trabalhamos com a questão das representações, Chartier (1990, p.17) nos lembra que na grande maioria das vezes as representações sociais são determinadas pelos grupos que as forjam. Dessa forma, seria interessante averiguar a relação existente entre o discurso promovido nas narrativas contidas nos livros didáticos e a apropriação das mesmas por aqueles que irão de certa maneira mediar à leitura e interpretação das mesmas.

Em se tratando dos conteúdos, o autor ainda aponta para o fato de que os mesmos não são selecionados de forma aleatória, são imbuídos de estratégias e práticas sociais, escolares e políticas que tendem a impor uma autoridade à custa de outros, por elas menosprezados, a legitimar um projeto reformador ou a justificar, para os próprios indivíduos, as suas escolhas e condutas (Idem).

É o que ocorre com os livros didáticos, quando levamos em consideração toda a complexidade que os envolve, ou seja, entendendo-os como objetos que não se constroem por si só, mas sim a partir de um contexto, que envolve as políticas que os definem como é o caso das exigências do currículo e do PNLD; o mercado, e, portanto, as exigências das editoras; as necessidades dos professores que de certa forma acabam sendo os "mediadores culturais" no processo de ensino e aprendizagem, enfim tudo aquilo que os permeia e que os torna reais.

Talvez, exatamente por conta dessa complexidade, é que estudiosos do assunto chamam nossa atenção para o fato de que algumas ideias ainda baseiam-se no mito de um Brasil forte e unificado construído por uma sociedade homogênea e pacífica, quando se sabe da existência de grupos sociais, culturais e economicamente diferentes (BITTENCOURT, 2003, p. 198).

No início da década de 1980 as propostas curriculares refletiam o contexto social e político que a sociedade brasileira passava. Embora 
imbuídas de concepções teóricas diferentes, a ideia era ampliar os objetos e o conceito de História através da investigação, trazer uma nova noção de História como um conhecimento que estivesse próximo da sociedade e das ações e relações que nela se constituem. Surgia uma necessidade em problematizar as experiências sociais vividas no cotidiano, assim como, incluir novos sujeitos até então silenciados ou excluídos (FONSECA, 1993, p. 85-86).

Deixemos claro que não existe de fato qualquer menção ou demanda sobre a obrigatoriedade ou a necessidade de estudar a história dos cristãosnovos nos livros didáticos, assim como também não existe qualquer movimento que esteja reenvidicando essa memória. No entanto, mesmo que timidamente, é possível verificar que desde a década de 1980 sua presença não foi ignorada em nosso território, e sua história vem sendo escrita nos processos históricos tratados pelos livros didáticos, pelo menos naqueles aos quais nos propusemos a pesquisar.

O que nos intriga é o lugar que os cristãos-novos ocupam nesses manuais escolares, ou seja, sem uma discussão mais aprofundada que busque desnaturalizar sua presença em nosso território, limitando o papel que exerceram na sociedade brasileira no período colonial e as heranças que nela deixaram e que ainda hoje se fazem presentes.

Dentre as possíveis discussões relativas à identidade dos cristãosnovos no conjunto das representações, destacamos como os autores dos livros didáticos que estamos analisando se referem ao cristão-novo; a compreensão que se faz sobre sua presença em nosso território, mais especificamente durante o período da colonização, observando os diferentes discursos e as possíveis interpretações; e, por último, a disposição das imagens trazidas nas obras, trazendo uma reflexão sobre a forma como estão dialogando com os textos propostos nos mesmos.

Comecemos pelas obras referentes à década de 1980 citadas anteriormente ( ambas voltadas para o $2^{\circ} \mathrm{grau}$ ). Em História do Brasil de Raymundo Campos o cristão-novo surge no seguinte contexto:

As árvores de pau-brasil localizavam-se especialmente na costa do Nordeste e da Bahia. A exploração era monopólio da 
Coroa portuguesa, ou seja, tratava-se de produto estancado. O governo da metrópole realizou periódicos arrendamentos pelos quais empresários particulares podiam explorar 0 produto. O primeiro destes arrendamentos foi concedido a Fernão de Noronha e outros comerciantes cristãos novos de 1501 a 1504 (CAMPOS, 1983, p. 33).

Este parágrafo, por exemplo, nos permite a possibilidade de explorálo a partir da historiografia que se dedica ao estudo dos cristãos-novos no Brasil, apontando-os como aqueles que teriam tido um papel decisivo no povoamento e colonização de nosso território. Tudo teria começado quando Fernão de Noronha passou a liderar um consórcio de cristãos-novos em nossas terras ao receber do rei $D$. Manuel o privilégio de arrendar o comércio do pau-brasil (VAINFAS; ASSIS, 2005, p. 45).

A análise poderia incorporar de forma mais esclarecedora a inclusão dos neocristãos no projeto colonizador português, atentando para os interesses e as relações que ali existiam. Também, admitindo-se a presença significativa desses personagens em nosso território em termos quantitativos, a análise poderia ter suscitado possíveis razões que teriam motivado sua vinda e que levaram ao seu estabelecimento.

Observemos outra passagem do mesmo autor, comentando o interesse holandês por nossas terras no período açucareiro: Os holandeses tinham certo conhecimento do terreno. Desembarcaram na praia do Pau Amarelo e avançaram para o Recife e Olinda, seus principais objetivos. Contavam com a ajuda de espiões, há algum tempo na terra, como o cristão - novo Antônio Dias, o "Papa Robalos" (CAMPOS, 1983, p. 46).

Aqui se denota alguns fatores que se aproximam da produção historiográfica pelo menos nesse período, como por exemplo, a existência de uma relação entre os cristãos-novos e os holandeses; indícios de que havia certa sociedade em relação ao fator que teria incentivado a invasão dos holandeses nessa região do Brasil; a participação dos cristãos-novos nos interesses que os holandeses demonstravam por nossa prática açucareira; e, por fim, a liberdade religiosa que parecia fazer parte do novo cenário ocupado e administrado pelos holandeses. 
Percebam, por exemplo, como a presença neocristã é vista sobre outra perspectiva no livro História do Brasil: Colônia, Império e República dos autores Francisco de Assis Silva e Pedro Ivo de Assis Bastos:

\begin{abstract}
A extração do pau-brasil, cujo nome deriva de sua cor avermelhada, era monopólio (estanco) régio. O primeiro grupo econômico a explorá-lo foi o dos cristãos-novos ( judeus convertidos), liderado por Fernando de Noronha, que arrendou o Brasil. (SILVA; BASTOS, 1983, p. 16).
\end{abstract}

Assim como na obra de Raymundo Campos, verificamos a participação econômica direta dos cristãos-novos no projeto colonizador português, e sua importância nos lucros obtidos pela Coroa durante a exploração do pau-brasil; o fato de ser o primeiro grupo a fazer parte das intenções comerciais de Portugal em relação ao Brasil; e, uma preocupação em dar significado, ainda que de forma bastante simples ao termo cristãonovo.

Quanto à abordagem feita sobre o cristão-novo no Brasil colônia, percebemos que ela se dá de uma forma mais restrita, no sentido de que tal personagem surge apenas no início do processo colonizador, dando a impressão de que seu interesse estava voltado exclusivamente para o aspecto econômico, e, também de que estiveram aqui somente neste período.

Levando-se em conta o fato de que desde a década de 1970 estudos já apontavam para importância de se estudar a vinda e a permanência desses agentes em nosso território, sabe-se que sua atuação foi muito mais complexa do que a apresentada pelos livros em questão.

Para que seja possível, discutir, relacionar e estabelecer alguns parâmetros entre as obras escolhidas para essa pesquisa, vamos agora observar e refletir sobre os manuais mais contemporâneos.

Comecemos então, pelo livro didático voltado para o Ensino Fundamental, mais especificamente, o manual da $6^{a}$ série que corresponde hoje ao 70 ano, sobre o título: História em projetos. Velhos mundos e mundos novos: encontros e desencontros - do século XV ao XVIII. Aqui, os cristãos-novos são citados indiretamente, por meio da obra História do 
Brasil de Boris Fausto que trata o período da invasão holandesa o Brasil do século XVII. A passagem utilizada pelas autoras em caixa de texto é a seguinte:

[Maurício de Nassau], que era calvinista, foi tolerante com os católicos e [...] com os israelitas. Os cristãos-novos que praticavam o antigo culto às escondidas, foram autorizados a professá-lo, abertamente. Duas sinagogas existiram no Recife na década de 1640 e muitos judeus vieram da Holanda (FAUSTO, 2002, p. 86 apud OLIVEIRA; MIUCCI; SANTOS, 2007, p. 213)

Ao tratar das convivências culturais no cotidiano das colônias francesas e holandesa, observa-se num primeiro momento que o box ( ou caixa de texto) em questão estaria supostamente dialogando com uma imagem da Sinagoga Kahal Zur Israel, disponibilizada no mesmo contexto. No entanto, a imagem não fornece qualquer tipo de informação que possa esclarecer a relação existente entre imagem/texto, dificultando, portanto, a capacidade de interpretação do leitor ${ }^{9}$.

Em relação ao papel desempenhado pelos cristãos-novos na região nordeste do país na época retratada, reconhece-se a existência de uma bibliografia bastante significativa, porém, verificou-se que o livro didático não apresenta uma abordagem problematizada em torno da questão. Também, foi observado que até o período holandês, o cristão-novo não aparece na escrita produzida pelos autores, tornando sua presença restrita a um único espaço e tempo. Não há uma descrição ou análise que esclareça ao leitor sobre quem é o cristão-novo, e ao utilizarem-se do termo cristãonovo no mesmo espaço em que estão sendo tratados os judeus, ou israelitas, dão a impressão de se tratar de sinônimos, levando a interpretações distorcidas sobre o assunto.

Considerando a forte presença desses personagens na região nordeste da colônia e a atuação que tiveram nos mais diversos setores daquela sociedade, o estudo em torno do cristão-novo de forma mais

9 Refletindo sobre as imagens nos livros didáticos, Bueno (2001) entende que a união texto/legenda/imagem, produzida pelos livros didáticos, resulta em registros históricos que primam pela exclusão da reflexão da imagem do quadro histórico, como documento de uma determinada época. 
apropriada proporcionaria uma melhor compreensão tanto do período, quanto das transformações ocorridas por conta da nova administração que ali havia se instaurado.

Vejamos agora o livro História da civilização ocidental e como e em que contexto o cristão-novo está sendo incorporado: "A resistência organizada pelo governador de Pernambuco não conseguiu deter o avanço dos holandeses. Estes foram ajudados por cristãos-novos (judeus convertidos) e por alguns índios e mestiços cansados da exploração portuguesa" (PEDRO; LIMA, 2005, p. 204).

Ao discutirem, no capítulo 15, Política européia e administração do Brasil, mais especificamente quando abordam o Brasil holandês, os autores trazem o cristão-novo sobre uma perspectiva limitada no que se refere à questão do tempo e do espaço. Entretanto, assim como observamos na obra de Francisco de Assis Silva e Pedro Ivo de Assis Bastos, História do Brasil: Colônia, Império e República, houve uma preocupação em significar o termo "cristão-novo", explicando - ainda que superficialmente - de quem se tratava, no caso do judeu convertido. Um outro aspecto curioso, é a forma como tal personagem está representado, ou seja, de forma atuante, resistente à dominação a qual estavam sujeitos.

Do ano de 2007, o livro História: texto e contexto, os cristãos-novos aparecem na figura dos judeus portugueses que haviam sido expulsos de Portugal em 1497, os quais de acordo com Janaína Guimarães da Fonseca e Silva em seu estudo sobre os cristãos-novos em Pernambuco faz o seguinte relato:

Muitos elementos estavam ligados por redes de parentesco e solidariedade com outros cristãos-novos dispersos pelo mundo, bem como os judeus de origem portuguesa, devido ao caráter recente da expulsão dos judeus de Portugal em 1496 e conversão forçada, em 1497 (SILVA, 1982, p. 13).

Vejamos então, a escrita produzida por Catelli Junior quando se refere aos mesmos:

Durante a ocupação holandesa, muitos judeus vieram para Pernambuco atraídos pela tolerância religiosa definida por 
Maurício de Nassau. Grande parte destes eram judeus portugueses que haviam sido expulsos de Portugal pela Igreja Católica e que viviam nos Países Baixos. Fundaram, no Recife, a sinagoga Tzur Israel ( Rochedo de Israel) em 1636. No curso da administração de Nassau, acabaram por servir como mediadores entre o novo governo e os negociantes locais, pois dominavam o idioma e tinham uma relação de fidelidade com a Holanda. Com a expulsão dos holandeses, muitos judeus tiveram de deixar a região, indo se refugiar em Nova York, nos Estados Unidos. $\mathrm{Na}$ atualidade, essa sinagoga pode ser considerada parte do patrimônio e da memória da presença judaica e da dominação holandesa em Pernambuco (CATELLI, 2007, p. 165).

Gostaríamos aqui, de elaborar algumas questões: a primeira delas situa-se na questão da tolerância religiosa que o autor afirma existir durante a administração Nassoviana. Ora, a literatura em torno da presença cristã-nova nesse período, aponta para a grande importância dos mesmos não só enquanto "mediadores entre o novo governo e os negociantes locais", quanto durante todo o processo de estabelecimento dos holandeses na região nordeste, ocupando cargos administrativos; como senhores de engenhos; comerciantes bem sucedidos; traficantes de escravos, etc. Uma outra questão é quando o autor se refere ao fim da ocupação holandesa e a fuga dos judeus para Nova York, dando a impressão que os cristãos-novos ou judeus portugueses - que ali estiveram, já não existiam mais. O único vestígio que indicaria sua existência seria a sinagoga Tzur Israel - a qual ele se refere em seu texto, como patrimônio e memória de uma presença judaica no Brasil e nada mais além disso. Concluímos nesta análise que as experiências compartilhadas e vivenciadas por esses agentes foram totalmente desconsideradas, assim como, as possíveis relações de conflito entre os cristãos-novos - envolvidos em uma série de atividades - e os demais habitantes da região.

Refletindo à cerca da escrita que se dá em torno dos cristãos-novos nas obras escolhidas para esse estudo, pode-se constatar que em relação às mais atuais, aquelas pertencentes à década de 1980, parecem tratar a questão do neocristão sobre uma perspectiva menos limitada e restrita, lembrando que: 
Quando o livro didático se constitui na única fonte de consulta, seja do aluno, ou do professor, pode-se conduzir a um entendimento único da história, tendo em vista, inclusive que pode passar despercebido o entendimento do livro como o resultado de um conhecimento produzidos por autores circunscritos a diferentes aspectos sócios-culturais, teóricos metodológicos, políticos-econômicos. (ALMEIDA, 2005, p. 80)

A discussão desse estudo não se dá em torno do tamanho do espaço dado aos judeus convertidos que viviam no Brasil quando este era colônia, mas sim chamar a atenção para as permanências e mudanças adotadas na produção didática nos últimos vinte anos, e, a distância que persiste entre aquilo que é produzido na academia e na escola.

Nos parágrafos que fazem referência ao cristão-novo, notamos uma simplificação da complexa existência dos cristãos-novos no Brasil colonial, onde não se discute as variadas formas de resistência, ou, as adaptações e negociações que foram constantes desde sua chegada. Tampouco se discute a organização social desses sujeitos históricos, impossibilitando se pensar nas heranças deixadas por eles na sociedade brasileira, além de uma forte contribuição étnica.

Contudo, embora a presença dos cristãos-novos no período colonial brasileiro tenha sido pouco explorada nos livros didáticos que aqui nos propusemos a investigar, o fato é que referente àqueles da década de 80 , se compararmos com as obras mais contemporâneas, curiosamente, percebe-se algumas diferenças. Uma delas seria em relação ao espaço de tempo em que o cristão-novo é tratado, ou seja, logo no início de nossa colonização; outra se deve ao papel que tal personagem vem desempenhar dentro desse cenário, isto é, ocupando a posição de um comerciante que estaria envolvido com a exploração do pau-brasil e nos lucros obtidos com a exploração do mesmo; quanto à relevância dos cristãos-novos em nosso território, o fato de estarem representados como ativos participantes das atividades comerciais na colônia, antes mesmo dos portugueses decidirem tomar posse de nossas terras, nos dá indício de uma provável relação com a Coroa, principal interessada neste processo.

Observando os textos que tratam do período açucareiro, seria interessante atentarmos para a forma como os cristãos-novos estão representados na escrita produzida pelos livros em questão. Ora, 
observando as obras mais atuais, num primeiro momento, a impressão que se tem sobre a presença dos cristãos-novos no período apontado, é que essa teria ocorrido apenas nessa época e, somente por causa da assim considerada "tolerância religiosa" por parte do governador Maurício de Nassau. Dessa forma, entende-se que a importância maior estaria na liberdade religiosa que Nassau teria concedido àqueles que não fossem católicos, e, não aos cristãos-novos que ali estavam propriamente. O que queremos dizer, é que devido à existência de uma vasta documentação sobre os cristãos-novos nesse espaço de tempo e, por conseguinte uma significativa produção historiográfica que abarca todo esse período em que estiveram lá estabelecendo relações, desenvolvendo laços, interagindo com o meio social, econômico, cultural, religioso e político, então talvez o papel desempenhado por esses sujeitos poderia ser melhor aproveitado.

Isso é o que pareceu-nos ocorrer com os livros da década de 80 . Ainda que esteja representado de forma superficial, o cristão-novo assume outro papel nos textos trazidos por eles, muito mais atuante e menos submisso. Ele aparece na figura de um espião a serviço dos holandeses, contribuindo para o êxito de seu estabelecimento em nosso território.

Também, demonstramos aqui, que em alguns textos o judeu e o cristão-novo aparecem na condição de um mesmo indivíduo, fato esse preocupante, tendo em vista que, segundo Antonio Borges Coelho em seu estudo sobre Cristãos-novos, judeus portugueses e o pensamento moderno (1998, p.254), não seriam legítimos nem verdadeiros usar os dois vocábulos, cristão-novo e judeu, como se de sinônimos se tratasse, podendo assim comprometer a imagem, ou a ideia sobre o que vem a ser um, ou o que vem a ser o outro.

Seria pertinente, que no início do texto as principais contribuições da historiografia fossem elencadas e de forma mais sistemática, organizada e evidente. Além disso, não se pode afirmar que ao analisar concepções presentes em livros didáticos o pesquisador está aferindo concepções da escola, mas, diga-se, presentes em impressos didáticos que sofrerão uso variado, plural e, esperamos, crítico na escola. 
Considerando que o estudo dos cristãos-novos no Brasil abrange um espaço significativo na historiografia, entendemos que a trajetória de tais agentes não pode ser ignorada nos manuais didáticos, ela torna-se indispensável na medida em que se apresentam enquanto parte integrante da história política, social, econômica, cultural e religiosa no dia-a-dia da sociedade brasileira colonial.

\section{Referências}

ABUD, K. O livro didático e a popularização do saber histórico. In MARCOS, A. da S. (Org.). Repensando a história. Rio de Janeiro: Marco Zero/ ANPUH, 1986.

. Conhecimento histórico e ensino de história: a produção do conhecimento histórico escolar. In: SCHMIDT, M. A.; CAINELLI, M. R. (Org.). Perspectiva do ensino de história III. Curitiba: Aos Quatro Ventos, 1999.

A História nossa de cada dia: saber escolar e saber acadêmico na sala de aula. In: Monteiro, Ana Maria e outros (Org.). Ensino de História. Sujeitos, saberes e práticas. Rio de Janeiro: Mauad, 2007.

ALMEIDA, J. P. de. A difusão do conhecimento científico sobre meio ambiente nos livros didáticos de História. História \& Ensino. Londrina, Ed. UEL, Revista do Laboratório de Ensino de História 2005, p. 75-94.

BELLOTTI, K. K.. Identidade, alteridade e religião na historiografia colonial. In: Artigo. Revista de História e Estudos Culturais. Campinas: UNICAMP, 2005.

BITTENCOURT, C. Identidade nacional e ensino de História do Brasil. In KARNAL, L. História na sala de aula: conceitos, práticas e propostas. São Paulo: Contexto, 2003, p. 185-2005.

BUENO, J. B. G. Tecendo reflexões sobre imagens pictóricas (do final do século XIX e início do século $\mathrm{XX}$ ) utilizadas nos livros didáticos no Brasil. IV Anais do Seminário Perspectivas de Ensino de História, Ouro Preto, 2001.

CARVALHO, F. M. Raízes judaicas no Brasil: o arquivo secreto da inquisição. São Paulo: Nova Arcádia,1992.

CARVALHO, F. M. C. de. O Brasil nas profecias de um judeu sebastianista: os "Aforismos" de Manuel Bocarro Francês/ Jacob Rosales. In Keila Grinberg. (org.). Os judeus no Brasil: inquisição, imigração e identidade. Rio de Janeiro: Civilização Brasileira, 2005. 
CHARTIER, R. A História Cultural: entre práticas e representações. Trad. Maria M. Galhardo. Lisboa: Difel, 1990.

COELHO, B. A. Cristãos-novos, judeus portugueses e o pensamento moderno. In NOVAES, A. (Org.). A descoberta do homem e do mundo. São Paulo: Companhia das Letras, 1998.

DEL PRIORE, M.; VENÂNCIO, R. P. O livro de Ouro da História do Brasil. Rio de Janeiro: Ediouro, 2003.

FANAIA, J. E. A. de. História, Saber Acadêmico e Saber Escolar: Um Diálogo Possível? Coletâneas do nosso tempo. Rondonópolis - MT, v. VII, n. 8, p.13-22, 2008.

FONSECA, T. N. de L. e. História \& ensino de História. Belo Horizonte: Autêntica, 2006.

FONSECA, S. G. Caminhos da história ensinada. São Paulo: Papirus, 1993.

GEERTZ, C. A interpretação das culturas. Rio de Janeiro: Ed. Guanabara, 1989.

HERMANN, J. As metamorfoses da espera: messianismo judaico, cristãosnovos e sebastianismo no Brasil colonial. In GRINBERG, K. Os judeus no Brasil: inquisição, imigração e identidade. Keila Grinberg (Org.). Rio de Janeiro: Civilização Brasileira, 2005, p. 87-111.

MIGUEL, L. F. Retrato de uma ausência: a mídia nos relatos da história política do Brasil. Revista Brasileira de História. São Paulo, v. 20, n.39, p.190-199. 2000.

NOVINSKY, A. Cristãos-novos na Bahia: a inquisição. São Paulo: Perspectiva, 1992.

.Ser marrano em Minas Colonial. Revista Brasileira de História. São Paulo: ANPUH/ Humanitas Publicações, v. 21, n· 40, p. 161-176. 2001.

OLIVEIRA, I. B. A zona do indeterminado: pensando autor, autoria, produção e consumo de livros didáticos. In OLIVEIRA, M. M. D. de; STAMATTO, M. I. S. (Org.). O livro didático de história: políticas educacionais, pesquisas e ensino. 01 ed. Natal: EDUFRN, 2007, v. 01, p. 67-73.

PERNIDJI, J. E. A saga dos cristãos-novos. Rio de Janeiro: Imago, 2005.

SALVADOR, J. G. Os cristãos-novos. Povoamento e conquista do solo brasileiro (1530-1680). São Paulo, Pioneira, 1976.

Os cristãos-novos e o comércio no Atlântico Meridional: com enfoque nas capitais do Sul, 1530-1680. São Paulo, Pioneira, 1978 
SILVA, J. G. da F. e. Modos de pensar, maneiras de viver: cristãos-novos em Pernambuco no século XVI. Dissertação de mestrado em História da Universidade Federal de Pernambuco. Recife, 2007.

VAINFAS, R.; ASSIS, A. A. F. A esnoga da Bahia: cristãos-novos e criptojudaísmo no Brasil quinhentista. In GRINBERG, K. (Org.). Os judeus no Brasil: inquisição, imigração e identidade. Rio de Janeiro: Civilização Brasileira, 2005, p. 43-63.

VAINFAS R; HERMANN, J. Judeus e conversos na Ibéria no século XV: sefardismo, heresia, messianismo. In GRINBERG, K. Os judeus no Brasil: inquisição, imigração e identidade. (Org.). Rio de Janeiro: Civilização Brasileira, 2005, p. $15-41$.

VALADARES, P. A presença oculta: genealogia, identidade e cultura cristãnova brasileira nos séculos XIX e XX. Fortaleza: Fundação Ana Lima, 2007.

WOLFF, E.; WOLLF, F. Os judeus no Brasil imperial. Uma pesquisa nos documentos e no noticiário carioca da época. São Paulo, Centro de Estudos Judaicos, 1975.

\section{Fontes:}

SILVA, F. de A.; BASTOS, P. I de A. História do Brasil: Colônia, Império e República. São Paulo: Moderna, 1983.

CAMPOS, R. História do Brasil. São Paulo: Atual, 1983.

CATELLI JR, R. História. Texto e Contexto. São Paulo: Scipione, 2007.

PEDRO, Al; SOUZA, L.; CARVALHO, Y. História da Civilização Ocidental. Integrada. Geral e do Brasil. São Paulo: FTD, 2005.

OLIVEIRA, M. da C. C.; MIUCCI, C.; SANTOS, A. P. História em projetos. Velhos mundos e mundos novos: encontros e desencontros - do século XV ao XVIII. São Paulo: Ática, 2007. 